\title{
Review of Research on Portfolios in ESL/EFL Context
}

\author{
Lijuan Wang ${ }^{1} \&$ Chunyan $\mathrm{He}^{1}$ \\ ${ }^{1}$ School of Foreign Languages, China University of Geosciences (Beijing), Beijing, China \\ Correspondence: Lijuan Wang, School of Foreign Languages, China University of Geosciences (Beijing), \\ Beijing, China.
}

Received: October 28, 2020

Accepted: November 16, 2020

Online Published: November 26, 2020

doi: 10.5539/elt.v13n12p76

URL: https://doi.org/10.5539/elt.v13n12p76

\begin{abstract}
The portfolio is considered a useful tool both for instruction and assessment. Properly designed and implemented, it provides authentic language material for assessment, increases learners' involvement in learning process and promotes self-reflection. This article mainly reviews the empirical research on portfolios in ESL/EFL context and offers suggestions for future research. The article starts by providing a brief introduction to portfolio and the framework for systematically designing and implementing portfolio assessment in the classroom. Then it reviews the empirical studies of portfolios in ESL/EFL context from three perspectives, i.e. portfolio assessment on writing, portfolios as a means to promote autonomy and e-portfolios. The article concludes by emphasizing the benefits of portfolios in language learning, indicating challenges in carrying out portfolio assessment, and providing suggestions for future research.
\end{abstract}

Keywords: assessment, empirical study, portfolios, portfolio assessment

\section{Introduction}

The pedagogical theory in second language acquisition has undergone dramatic changes in the last two decades. The shift of the emphasis from the teaching approach to the learners resulted in more attention to students' participation and progress. Under such circumstance, portfolio assessment as a useful tool for instruction and assessment has been adopted by language teachers and researchers.

\subsection{Definition of Portfolio}

A portfolio has originally been used to be a collection of artists' work and samples of their achievements. When it is used to language teaching and learning, the portfolio has a range of definitions, reflecting the diversity and complexity of its use (Nunes, 2004). The general definition proposed by some researchers is the purposeful collection of student work that exhibits the student's efforts, progress, achievements and reflection in one or more areas of the curriculum (Paulson, Paulson \& Meyer, 1991). Different teachers may use it in different ways and for different purposes. Some teachers use it for an alternative assessment, and then it will include the best work and the achievement of the students; some use it to document and monitor the student's learning process and promoting students' autonomy; and others use it as a means of self-reflection.

\subsection{Benefits, Problems and Framework of Portfolio Assessment}

A wide range of research in the past three decades has documented the benefits of the portfolio assessment and supported its use in EFL classrooms (Padilla et al., 1996; Hamp-Lyons \& Condon, 2000; Moya \& O'Malley, 1994; Delett et al., 2001). These benefits include: portfolios offer a "multidimensional perspective of student progress over time" (Delett et al., 2001, p. 559); they provide "accurate information about the breadth of a student's capabilities in many domains of learning" (Moya \& O'Malley, 1994, p. 17); they encourage students' participation in the learning process and self-reflection through goal-setting section and reflective journal. Portfolio assessment links assessment with teaching and learning, offering the students a realistic assessment and providing them with opportunities to adjust their learning strategies. Compared with traditional assessment, portfolio assessment facilitates the teacher-student interaction and involves students and teachers in the learning process. (Delett et al., 2001)

However, despite the effectiveness and potential benefits of portfolios, there are also disadvantages of using portfolios as an assessment, such as difficulty to determine the grading criteria, too much time needed to compile and read portfolios, and uncertainty about what to be contained in the portfolio etc. (Brown \& Hudson, 1998). 
Teachers also report difficulties implementing portfolio assessment successfully in their own classroom due to its complexity (Calfee \& Perfumo, 1993; Padilla et al., 1996).

Delett et al. (2001) then provides a framework to guide teachers to systematically design and implement portfolio assessment. The framework contains seven steps and can be used in any instructional context (Delett et al., 2001). The seven steps are as follows:

Step 1 plan the assessment purpose

Step 2 determine portfolio outcomes

Step 3 match classroom tasks to outcomes

Step 4 determine organization of the portfolio

Step 5 establish criteria for assessment

Step 6 monitor the portfolio process

Step 7 evaluate the portfolio process.

(Delett et al., 2001, p. 560)

\section{Literature Review}

Numerous studies have been done to delve into the function and application of portfolios and portfolio assessment in ESL and EFL context. The body of literature concerning portfolios in ESL/EFL is mainly divided into three categories: assessment on writing, promoting autonomy and e-portfolio. This paper intends to review the research in recent years from these three perspectives.

\subsection{Portfolio Assessment on Writing}

Portfolios were originally brought into education circle as an alternative assessment to traditional assessment mode because standardized tests were criticized for the "incompatibility of process learning and product assessment" (Moya \& O'Malley, 1994, p. 16). Numerous studies investigated the feasibility of portfolio assessment on ESL writing. In the late 1980s and early 1990s, the timed test, which is usually placed at the end of the course, is considered inconsistent with the whole process of teaching and learning this complex skill (Park, 2004). Traditional test usually requires students to accomplish a composition based on a given topic without time to revise and no freedom to choose topics. Then portfolio assessment as an alternative to traditional assessment emerged. Portfolios contain multiple samples of students' writing which "are produced potentially free from the negative effects of test anxiety and without the typical time constraints of an exam" (Kroll, 1998, p. 231). Thus, portfolio assessment provides a useful evaluation approach through reflecting directly the goal of writing instruction and by integrating instruction with assessment. (Moya \& O'Malley, 1994) Three advantages of portfolio assessment on writing have been listed: it provides teachers with more evidence and a broader range of samples for judgment (Hamp-lyons \& Condon, 1993); it encourages learners to take ownership of their learning and reflect on the writing process (Murphy, 1994). Composed of several drafts of students' writing and different type of learning, writing portfolios pay attention to the writing process (Murphy, 1994) and are in accordance with process-oriented teaching approach.

Quite a few studies are conducted to investigate the effects of portfolio assessment on writing (Song \& August, 2002; Hirvela, 2005; Lam \& Lee, 2010; Romova \& Andrew, 2011). Lam \& Lee (2010) compared the dual functions of portfolio assessment on English writing: formative and summative assessment, in one Hong Kong University, where students were required to submit several drafts of their writing, collecting them in their portfolios and selecting two for summative assessment. The findings indicated that while students displayed positive attitude to formative assessment, they preferred the summative grading because they tended to believe only grade could reflect their written competence. In a quantitative study done by Song \& August (2002), the researchers compared the performance of two advanced ESL students in the second semester course. One group was assessed by portfolios and writing assessment test (WAT), while the other group was only evaluated by WAT. The portfolio group could move to the next period based on the progress in their portfolios regardless of their WAT scores, while the other group was permitted to advance to the higher-order class only when they passed WAT. Then the author compared the students' passing rate and the subsequent performance in the English course of the two groups. She found that because the number of ESL learners evaluated by portfolio assessment, who proved successful in the later English course, was twice as many as the students who passed writing assessment test, portfolio assessment seemed to be a more appropriate assessment approach to writing. Romova \& Andrew (2011) examined the role of portfolios as a tool to promote academic writing in a tertiary institution in New Zealand. 41 cross-cultural students were included in the study and qualitative data were collected through 
questionnaire and students' reflection. The findings supported the idea that portfolio assessment through multi drafting turned out to be an effective assessment tool. Multi-drafting process enabled students to acquire both academic literacy (referencing, summarizing, paragraph and text structuring, paraphrasing) and process-oriented writing strategies (prewriting, outlining, drafting, redrafting and proofreading). The reflection also encouraged students to develop critical thinking, and acquisition of academic language.

The perceptions of ESL writers have also been studied to show students' attitude towards portfolio assessment on writing (Aydin, 2010; Hirvela, 2005). The study of Aydin (2010) investigated the perceptions of 204 college students about portfolio keeping. It demonstrated that although portfolio keeping in EFL writing was beneficial to the improvement of vocabulary and grammar knowledge, reading and writing skills, and organizational ability, learners also thought "it is tiring, boring and takes too much time, and they have difficulty in pre-writing task, feedback and rewriting process" (Aydin, 2010, p. 199). Besides, the perceptions of students did not reveal any effects of portfolios on motivation and learning autonomy, which is contrary to previous hypothesis. The study of Hirvela (2005) examined two case studies, investigating ESL students' perceptions about two different portfolio models: the selected portfolios (students select the samples of their writing) and comprehensive portfolios (students include any assignments they have written). Portfolios used in this study were implemented in an ESL classroom setting, and they were learning-directed that focused more on pedagogic purpose than assessment portfolio orientation. The findings revealed that one student preferred selected portfolios, while the other liked comprehensive portfolios. Although the two students involved in this study did not display negative attitude to the implementation of portfolios (esp. comprehensive portfolios), they did not show too much enthusiasm and did not have meaningful reflection as expected. Hirvela argued that the portfolio implementation turned out to be a failure because the instructors failed to create a "portfolio culture" to help the students fully understand what pedagogic meaning the instructors intend to achieve by using portfolio assessment and also failed to engage the students more actively in the reflection. She suggested that instructors should maintain lasting focus on and commitment to portfolios in order to successfully implement portfolio assessment in the ESL classroom.

Bader et al. (2019) investigated the students' perceptions of formative feedback as part of portfolio assessment in Norway. From the 128 reflection notes written by student teachers of English, they found that students attached great importance to teacher feedback and considered it significant, while students thought the peer feedback lack constructive criticism. This study may draw our attention to the role of self-assessment and peer assessment, which were believed to be distinctive features of portfolio assessment.

From the review of studies on the portfolio assessment of writing, it can be concluded that most of the studies are qualitative, which are mainly based on questionnaire, interview or reflective journal. Most studies agree that portfolio assessment is an effective assessment tool and is conducive to the improvement of writing skills. However, issues such as the criteria of grading and incompatibility of students' perception still remain.

\subsection{Portfolios as a Means to Promote Autonomous Learning}

Autonomy is defined as the ability of taking responsibility for one's learning (Benson, 2001). The recent shift from teacher-centered to student-centered learning reinforces the importance of autonomous learning. One of the functions of the portfolio is to empower the students to focus on the process of learning, and to increase the students' participation and involvement in the learning process by teaching the learners to set goals and plan for learning, monitor their learning process and reflect on the process. These actions are called metacognitive strategies, the essential component of autonomous learning. Some researchers view the function of portfolios from the perspective of improving autonomous or self-regulated learning. (Moeller, et al., 2012; Ziegler, 2014; Lo, 2010; Gonzalez, 2009; Nunes, 2004; Yang, 2003).

There are two prevailing portfolios that are implemented in second and foreign language learning all over the world: European Language Portfolio and Lingofolio in America. Both of them contain similar parts, such as language passport (the assessment of students' proficiency), language biography (set language targets, monitor progress, and reflect on learning experience), dossier (a selection of work that represents learners' proficiency). They were introduced to ESL/EFL classroom about one decade ago. Recently, some researchers attempted to examine their role in promoting self-regulated learning.

Moeller et al. (2012) conducted a 5-year longitudinal quantitative study in Spanish language classroom of high school. LinguaFolio was introduced to 1273 students with the purpose of investigating the relationship of goal setting and student achievement. Goal setting is considered an important strategy in promoting learner autonomy (Moeller et al., 2012). Just as mentioned above, linguaFolio is a kind of portfolio that mainly intends to enhance students' autonomy through students' self-assessment, goal-setting, and collection of evidence of language attachment. The linguaFolio goal-setting process in this study mainly includes three parts: "setting goals, 
establishing an action plan for goal attainment, and reflecting on relative attainment of goals" (p. 158). The findings demonstrated a positive relationship between goal setting process and the language proficiency. That is to say, the more practiced and skilled a learner is at goal setting, the higher language achievement will be made. Ziegler \& Moeller (2012) conducted a similar study to investigate the use of LinguaFolio as an innovative intervention and formative assessment to improve self-regulated learning. The study was a quasi-experimental and quantitative one. The findings showed that the increased frequency of the use of linguaFolio led to higher intrinsic motivation, increased task value, and more accurate self-assessment ability.

Two studies were carried out to examine the role of a similar portfolio model in Europe-the European Language Portfolio (Ziegler, 2014; Gonzalez, 2009). ELP is an alternative assessment used in foreign language classes throughout Europe to record language learning based on process-oriented teaching approach. ELP has two functions: "pedagogical function and reporting function "(Gonzalez, 2009, p. 374) According to Kohonen (2007, cited from Gonzalez, 2009, p. 374), the pedagogic function emphasizes the process aspect: helping students to set goals, make plans, reflect and monitor the learning process, and the reporting function is concerned with product aspect: providing a record of language skills. Gonzalez (2009) investigated the use of ELP in two adult language schools in Spain and found that students preferred the pedagogical function to the reporting function. The students also encountered some problems, such as difficulty of self-assessment and the bulkiness of format, to which solutions were provided. The implementation of ELP greatly enhanced students' awareness of autonomous language learning and developed a "metacogitive understanding of language" (Kohonen, 2007, cited from Gonzalez, 2009, p. 381). Students were also convinced of the significance of learning outside of the classroom. In a subsequent research, Ziegler (2014) confirmed the function of ELP in increasing students' capacity for self-regulated learning through the processes of self-assessments of ability, strategy building, goal-setting and self-reflection. Mixed methods were employed and 575 primary students in Germany were recruited as participants. This study provided convincing empirical evidence to support the pedagogic purpose of ELP.

Researchers in Asian countries started to show a growing interest in portfolios and its role of promoting autonomy since the last decade (Yang, 2003; Lo, 2010). They analyzed the possibility of implementing portfolio projects in an Asian context.

In the study of developing reflective portfolios to promote autonomous learning in a course of journalistic English in Taiwan, Lo (2010) have found that through the portfolio students learn to actively engage in multi-domain learning, which are cognitive, affective, social and metacognitive domains, and also develop a holistic approach to language learning. 101 college students participated in the study. The study was described in detail which could help readers have a complete understanding about the whole picture. The students involved in the study had no previous experience of compiling portfolios. During the study the students were required to compile portfolios about English newspapers. The findings also echoed the previous findings that portfolios can lead to the improvement of the awareness of autonomous learning. Problems that have been identified are students are unfamiliar with critical reflective thinking and peer evaluation. Lo then suggested that peer evaluation and instruction in critical thinking should be incorporated into EFL teaching. Yang's (2003) study mainly analyzed the portfolio implementation in strategy-based instruction. The portfolio used in this study contained a variety of material including reading report sheets, weekly listening logs, news story summaries, vocabulary logs, highlighting the process-oriented function of portfolios. Therefore, the purpose of using portfolios in this study was to record the learning process and enhance students' metacogtive strategies. The result revealed that portfolios could promote the use of metacogtive strategies and motivate active learning. However, the students also reported some problems such as "some students fake record"; "it is time-consuming" etc. Moreover, the evidence of improving language proficiency through portfolio implementation was ambiguous.

All These studies reached an unanimous agreement that portfolios could promote autonomous learning or help students develop metacognitive strategies.

\subsection{E-Portfolio}

With the development of information technology, there is an increasing interest in e-portfolios. Al Kahtani (1999, cited from Cummins \& Davesne, 2009, p. 262) defined an electronic portfolio as "a purposeful collection of a student's work that is made available on the World Wide Web or a recordable CD-ROM". The advantages of e-portfolios are listed as being portable, easy to share with peers or teachers, and capable of storing a wide variety of media files (e.g. audio files, video files, movies, photos, text files, PowerPoint) (Cummins \& Davesne, 2009). Not constrained by time and place, an e-portfolio makes it easier for teachers and peers to give feedback. 
Thus, the e-portfolio provides students with such a personal space where they can write, revise their writing, give and receive feedback. (Baturay \& Daloğlu, 2010)

Chang et al. (2004) attempted to incorporate e-portfolios into language teaching in Taiwan. The study gave a detailed description of the procedures to implement e-portfolios in a Taiwan junior high school. The students were taught to build webpage which included four components: homepage, recorded speaking, digital Mother's Day card and students' diary. The data collected from the questionnaire indicated that this experiment received overwhelmingly positive reaction from the participants. However, some practical problems related to e-portfolios also arose. For example, language teachers had little knowledge about digital technology; e-portfolio software was not always available for application etc. (Aydin, 2014). Some researchers recommend social network for e-portfolio, such as blog (Huang \& Hung, 2010), or Facebook (Aydin, 2014).

Huang \& Hung (2010) examined the effects of e-portfolios on EFL oral performance through a study conducted on college students in Taiwan. Although extensive empirical studies have been conducted concerning portfolio assessment, very few studied its effect on oral competence. E-portfolio makes it possible since it enables learners to record their oral assignment and present them on the web. The researchers presented very encouraging findings. 30 college students from two oral English classes were divided into control group and e-portfolio group. The e-portfolio group was supposed to post their audio assignment on blog, while the control group only recorded their speaking in compact disks and handed them to the teacher. The study found that the students who used e-portfolio produced larger quantity of oral production than the control group, and lexicon richness was also greatly improved. However, e-portfolio failed to affect the syntactic complexity. Besides, students exhibited positive attitude towards e-portfolios in that this innovative practice provided students with more language practice, alleviated their anxiety of speaking and enabled them to repeatedly revise and monitor their learning process.

With the popularity and wide use of Facebook in communication, interaction and information exchange in recent years, scholars attempted to incorporate it into ESL. In a study conducted in Philippine, Barrot (2016) explored the impact of Facebook-based e-portfolio on ESL students' writing practices and problems they encountered in implementing such kind of e-portfolio. The subjects involved in the study were required to publish their writing on the class Facebook account in the format of PowerPoint, and they were also encouraged to provide feedback to their classmates' writings. The result revealed that Facebook based e-portfolios had positive impact on ESL students' writing practices, by providing opportunities for students to edit their writing electronically, exhibit their best work, reflect on their work and monitor the writing process. Challenges students encountered were mainly technical problems and embarrassment or anxiety to present their writing to the public. Contrary to the previous study, this study did not find evidence to prove e-portfolios could reduce students' anxiety.

E-portfolios as a novelty attract increasing attention in recent years. The aforementioned three studies agreed on one point: students embrace this innovative practice with enthusiasm, and hence, e-portfolios seem to be even superior to regular portfolios. This may be because e-portfolios accommodate the needs of the new generation brought up in information age, who like to communicate and share stuff with each other in the virtual world.

\section{Conclusion}

As an innovative and useful tool for instruction and assessment, portfolios offer a holistic picture of the learners' learning process and progress, encourage learners to take full responsibility for their learning and foster learners' autonomy. The empirical evidence has been documented to confirm the benefits of portfolios for serving as formative and summative assessment of writing, promoting students' autonomy by teaching them to set goals, design plans and reflect on the learning process, or developing students' specific language skills. The introduction of European Language Portfolio and linguaFolio in America is to take advantage of these benefits in ESL and EFL classroom and provides new opportunities for researchers. The development of information technology enables researchers to incorporate the new technology into portfolio practice and leads to the creation of e-portfolios. Difficulties or challenges about portfolio assessment are also found, including difficulties in determining the criteria of grading, difficulties in self-assessment, ineffectiveness of peer assessment, heavy workload both for students and teachers etc.

However, despite the wide range of literature on portfolios, still there are some fields that have not been fully probed into. There are relatively few studies on the effects of portfolio assessment on specific skills other than writing, such as speaking, listening and reading or its implementation in specific courses. Case study is required to provide a thick description of the whole picture. The future research may also pay attention to the E-portfolio to explore its application on different electronic platforms or with different formats.

It is not easy to implement portfolio assessment in language classroom because it needs careful plan and 
preparation to ensure that the content, outcome and assessment criteria are suitable for certain teaching goals. Teachers need to adapt portfolios to their own teaching circumstances. Moreover, systematic research on the success and problems of portfolios in various educational settings need to be conducted.

\section{Acknowledgements}

The authors would like to sincerely express thanks for the support by the Fundamental Research Funds for the Central Universities under Grant 2652018331.

\section{References}

Aydin, S. (2010). EFL writers' perceptions of portfolio keeping. Assessing writing, 15(3), 194-203. https://doi.org/10.1016/j.asw.2010.08.001

Aydin, S. (2014). EFL Writers' Attitudes and Perceptions toward F-Portfolio Use. TechTrends, 58(2), 59-77. https://doi.org/10.1007/s11528-014-0737-6

Bader, M., Burner, T., \& Varga, Z. (2019). Student perspectives on formative feedback as part of writing portfolios. Assessment \& Evaluation in Higher Education, 44(7), 1017-1028. https://doi.org/10.1080/02602938.2018.1564811

Barrot, J. S. (2016). Using Facebook-based e-portfolio in ESL writing classrooms: impact and challenges, Language, Culture and Curriculum, 29(3), 286-301. https://doi.org/10.1080/07908318.2016.1143481

Baturay, M. H., \& Daloğlu, A. (2010). E-portfolio assessment in an online English language course. Computer Assisted Language Learning, 23(5), 413-428. https://doi.org/10.1080/09588221.2010.520671

Benson, P. (2001). Teaching and researching autonomy in language learning. London: Longman.

Brown, J. D., \& Hudson, T. (1998). The alternatives in language assessment. Tesol Quarterly, 32(4), 653-675. https://doi.org/10.2307/3587884

Calfee, R. C., \& Perfumo, P. (1993). Student portfolios: Opportunities for a revolution in assessment. Journal of reading, 36(7), 532-537.

Chang, Y. J., Wu, C. T., \& Ku, H. Y. (2004). The introduction of electronic portfolios to teach and assess English as a foreign language in Taiwan. TechTrends, 49(1), 30-35. https://doi.org/10.1007/BF02784902

Cummins, P. W., \& Davesne, C. (2009). Using electronic portfolios for second language assessment. The Modern Language Journal, 93(s1), 848-867. https://doi.org/10.1111/j.1540-4781.2009.00977.x

Delett. J. S., Barnhardt, S., \& Kevorkian J. A. (2001). A framework for portfolio assessment in the foreign language classroom. Foreign Language Annals, 34(6), 559-568. https://doi.org/10.1111/j.1944-9720.2001.tb02103.x

Gonzalez, J. A. (2009). Promoting students autonomy through the use of the European Language Portfolio. ELT Journal, 63(4), 373-382. https://doi.org/10.1093/elt/ccn059

Hamp-Lyons, L., \& Kroll, B. (1996). Issues in ESL writing assessment: An overview. College ESL, 6(1), 52-72.

Hamp-Lyons, L., \& Condon, W. (2000). Assessing the portfolio: Principles for Practice, Theory and Research. Cresskill, NJ: Hampton Press, Inc.

Hamp-Lyons, L., \& Condon, W. (1993). Questioning assumptions about portfolio-based assessment. College Composition and Communication, 44(2), 176-190. https://doi.org/10.2307/358837

Hirvela, A., \& Sweetland, Y. L. (2005). Two case studies of L2 writers' experiences across learning-directed portfolio contexts. Assessing Writing, 10(3), 192-213. https://doi.org/10.1016/j.asw.2005.07.001

Hung, HTD., \& Hung, STA. (2009). Promoting self-assessment strategies: An electronic portfolio approach. Asian EFL Journal, 11(2), 129-146.

Kroll, B. (1998). Assessing Writing Abilities. Annual Review of Applied Linguistics, 18, 219-240. https://doi.org/10.1017/S0267190500003561

Lam, R. (2013). Two portfolio systems: EFL students' perceptions of writing ability, text improvement, and feedback. Assessing Writing, 18(2), 132-153. https://doi.org/10.1016/j.asw.2012.10.003

Lam. R., \& Lee. I. (2010). Balancing the dual functions of portfolio assessment. ELT journal, 64(1), 54-64. https://doi.org/10.1093/elt/ccp024 
Lo. Y. F. (2010). Implementing reflective portfolios for promoting autonomous learning among EFL college students in Taiwan. Language Teaching Research, 14(1), 77-95. https://doi.org/10.1177/1362168809346509

Mathews, T. J., \& Hansen, C. M. (2004). Ongoing assessment of a university foreign language program. Foreign Language Annals, 37(4), 630-640. https://doi.org/10.1111/j.1944-9720.2004.tb02429.x

Moeller A. J., Theler, J., \& Wu, C. R. (2012). Goal setting and student achievement: A longitudinal study. The Modern Language Journal, 96(2), 153-169. https://doi.org/10.1111/j.1540-4781.2011.01231.x

Moya, S. S., \& O'Malley, J. M. (1994). A portfolio assessment model for ESL. The Journal of Educational Issues of Language Minority Students, 13(1), 13-36.

Murphy, S. (1994). Portfolios and curriculum reform: Patterns in practice. Assessing Writing, 1(2), 175-206. https://doi.org/10.1016/1075-2935(95)90022-5

Nunes, A. (2004). Portfolios in the EFL classroom: Disclosing an informed practice. ELT Journal, 58(4), 327-335. https://doi.org/10.1093/elt/58.4.327

Padilla, A. M., Aninao, J., \& Sung, H. (1996). Development and implementation of student portfolios in foreign language programs. Foreign Language Annals, 29(3), 429-438. https://doi.org/10.1111/j.1944-9720.1996.tb01254.x

Park, T. (2004). An Overview of Portfolio-based Writing Assessment. Working Papers in TESOL \& Applied Linguistics, 4(2).

Paulson, F. Leon, Peal R. Paulson, \& A. Meyer. (1991). What makes a portfolio a portfolio? Educational Leadership, 48(5), 60-63.

Romova, Z., \& Andrew, M. (2011). Teaching and assessing academic writing via the portfolio: Benefits for learners of English as an additional language. Assess Writing, 16, 111-122. https://doi.org/10.1016/j.asw.2011.02.005

Song, B. L., \& August. B. (2002). Using portfolio to assess writing of ESL writing: a powerful alternative? Journal of Second Language Writing, 11, 49-72. https://doi.org/10.1016/S1060-3743(02)00053-X

Yang. N. D. (2003). Integrating portfolios into learning strategy-based instruction for EFL college students. International Review of Applied Linguistics, 41, 293-317. https://doi.org/10.1515/iral.2003.014

Ziegler, N. A. (2014). Fostering self-regulated learning through the European Language portfolio: An embedded mixed methods study. The Modern Language Journal, 98(4), 921-936. https://doi.org/10.1111/modl.12147

Ziegler, N. A., \& Moeller, A. J. (2012). Increasing Self-Regulated Learning Through the LinguaFolio. Foreign Language Annals, 45(3), 330-348. https://doi.org/10.1111/j.1944-9720.2012.01205.x

\section{Copyrights}

Copyright for this article is retained by the author(s), with first publication rights granted to the journal.

This is an open-access article distributed under the terms and conditions of the Creative Commons Attribution license (http://creativecommons.org/licenses/by/4.0/). 